\title{
Torture Journal Annual Report 2017 - excerpts
}

\author{
A note from the editor and an update from the team
}

\begin{abstract}
Dear reader,
Thanks to all our readers and authors for making this journal-your journal-a true space of exchange. It belongs to you and those that contribute by sharing their research and reflections, by contributing to debates and reviews. We are especially thankful to our peer-reviewers, who silently and invisibly work behind the scenes, and are committed to helping authors in refining data and re-writing papers (see page 17 for a special thank you).

The Torture Journal seeks to be the place of reference for academia as well as field research within the disciplines of medicine and psychology while taking an interdisciplinary view. As an exercise in accountability, we would like to provide our readers with a summary of key elements from the journal's Annual Report. Your feedback will be welcomed.

Pau Pérez-Sales, Editor in Chief*
\end{abstract}

\section{Aims and objectives}

Academia and funding bodies often require publication in journals with the highest Impact Factor and field workers and clinicians often seek practical dissemination methods. We continue to strive to fulfil these two parallel and we think not mutually exclusive aims.

Torture Journal is a medical and psychological publication that aims to serve all professionals working with the rehabilitation of victims and prevention of torture. Its objectives are to:

- be a reference source for practitioners;

- promote and lead research in the field;

- foster debate on key topics within the scope of the journal; and,

- be a collective expression of the whole sector and to facilitate networking. Additionally, the Torture Journal has always played and continues to play a crucial part of fulfilling the strategy of its publisher, the International Council for Rehabilitation for Torture Victims. This is most recently set out in one of the key outputs agreed by the IRCT Council in December 2017, the Global Knowledge Platform. ${ }^{1}$

\section{Indicators}

Key points of interest

- The number of submissions has increased by four times in 2017 , the highest number of submissions in its historical series.

- The time from submission to publication

$1 \quad$ Please see https://irct.org/media-and-resources/ latest-news/article/948 for more information
*) $\mathrm{MD}, \mathrm{PhD}, \mathrm{Psych}, \mathrm{SiR}[\mathrm{a}]$ Centre Spain. Correspondence to: pauperez@arrakis.es 
reduced from 9 months (2016) to 12 weeks (2017).

- There remains a low rejection rate $(18 \%)$ due to the strategic decision of the Board to strongly support authors in their work, especially with contributions from Low and Middle Income countries.

- DOI has been introduced and the journal has become more searchable on the internet. The number of citations per document has increased from 0.47 (2016) to 1.09 (2017)

- SJR Impact factor has doubled from 0.18 (2016) to 0.34 (2017).

- The journal has a leading role in the field. $29.4 \%$ of all papers included in Medline in the 2016-17 period with the word 'torture' in the title were published in Torture Journal.

- The number of authors submitting papers from a country from the Low and Middle Income Countries increased threefold. Over 25 authors who had never published before, but who had presented ground-breaking work in formal or informal spaces, have been contacted and encouraged to submit papers. 14 of these contacts ended in

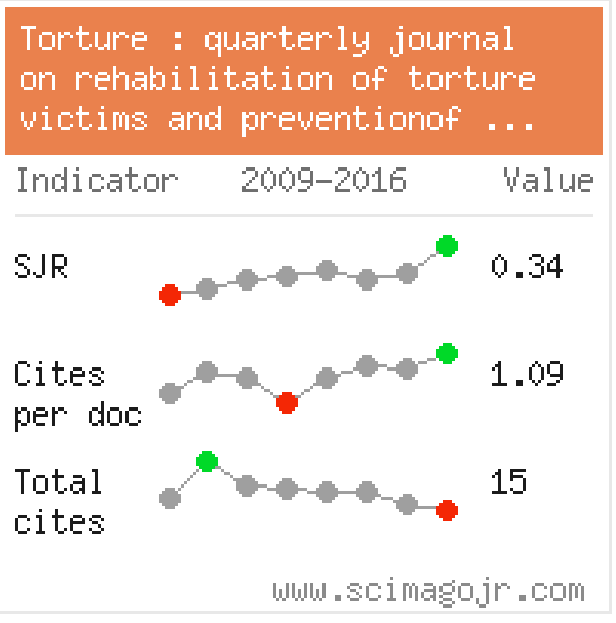

submissions, some of them through a mentoring process with the support of the Editorial Advisory Board.

- The journal would like to be a space for the entire anti-torture sector and continues to welcome papers from authors who do not belong to IRCT member centres. $60 \%$ of papers published by the journal are from authors that do not belong to an IRCT member centre.

- The journal has worked with partners, such as the International Society for Health and Human Rights and the European Network of Centers for Rehabilitation of Torture Survivors to provide space for highlights of their symposiums and conferences. Similar agreements with other networks or organisations are considered a priority.

\section{Contents}

- The journal now accepts a variety of contributions and maintains a wider number of sections, including an editorial, research and scientific papers, review articles, case reports, perspectives, news, statements, book reviews, letters to the editor and invites comments on scientific papers. ${ }^{2}$

- In 2017, papers included essays, personal reflections or conceptual debates (32\%), systematic reviews or meta-analyses (5\%), experimental studies $(50 \%)$, including psychometric studies (50\%); epidemiology (10\%); clinical cases-medical documentation (5\%), monitoring and evaluation of rehabilitation programmes $(20 \%)$, other $(10 \%)$ and anthropological or qualitative studies (15\%).

2 Intructions for authors can be found here: https:// tidsskrift.dk/torture-journal/information/authors 


\section{Improvements to the Journal}

- A new Open Journal Systems platform is now used in addition to the IRCT website to allow for better usability and a more professional interface for communication between the editors and authors and peer reviewers. ${ }^{3}$ The new platform importantly allows for back copies to be more searchable both directly and via Google and other search engines.

- Importantly, the platform allows for additional materials to papers (i.e. translations, databases, videos or other materials) to be uploaded. Authors are encouraged to submit, along with their papers, all the additional material they would like to be considered. We especially encourage authors to submit papers in the original language in addition to the English version.

- We promote issues and specific articles through press releases, social media and author networks.

The Delphi Study

A modified Delphi study with three rounds of consultation was carried out in 2017 to reach a consensus of expert panellists with respect to the top research priorities in the field of torture rehabilitation and prevention (see the last issue of Torture, 2017-3). Aims were to stimulate an interdisciplinary debate, foster research and inform the future publishing priorities of the Torture Journal. The results help to draw up a road map for the journal to be following in the coming three to five years.

The future

The following topics are to be the focus of issues or sub-sections in the coming year and a half. We encourage readers to submit articles and/or read them!:

- Forced Migration and Torture: challenges and solutions in rehabilitation and prevention, kindly subsidised by the Danish Research Ministry (May/June).

- Perspectives on sexualized torture and gender-based torture in the anti-torture sector (September/October).

- Long-term efficacy of torture rehabilitation, with a focus on the Balkans (first priority of the Delphi Study) (tbd).

\section{Financial situation}

Torture Journal is the leading journal in medical and psychological research related to the work with torture survivors. It remains open access and free to subscribers and readers. The Torture Journal, kindly supported by the International Rehabilitation Council for Torture Victims, faces serious funding issues.

The following measures are therefore being considered:

- Introducing a fee for up-to-date and back print copies for subscribers in the Global North and libraries and institutions globally.

- Asking IRCT member centres, academic institutions and organisations or others for contributions to the running costs. If you think you can contribute to this collective endeavour and help keep the Journal free and open access, please, contact us at irct@irct.org or donate via the link on the IRCT's website. ${ }^{4}$

Many thanks for your continued interest in the Torture Journal and we hope you enjoy reading this issue! 
On behalf of the Editorial Team and Editorial Advisory Board
Many thanks to our peer reviewers!
Adrienn Kroó

Aida Alayarian

Aida Seif

Alberto Fernandez Lira

Alvin Tay

Amanda Williams

Andrew Jefferson

Antii Sanjantila

Anton van Kalmthout

Astrid Kamperman

Benito Morentin

Bhava Poudyal

Birgit Lie

Blerina Kellezi

Boris Friele

Brock Chisholm

Cæcilie Buhman

Carla Uriarte

Clemens Ley

Clifford Perrera

Craig Higson-Smith

Daniel Weishut

Daryn Reicherter

Dastan Salehi

David Rhys Jones

Duarte Vieira

Elizabeth Stanley

Esther Pino Gamero

Ezat Mossallanejad

Farzad Pakzad

Felicitas Treue

Francisco Jose Eiroa Orosa

Francisco Orengo García

Fredrik Saboonchi

Gabriel Diaconu

Graciela De Cors
Gary E. Poole

Gonzalo Martínez-Alés

Guy Willems

Hanneke Bot

Hans Draminsky Petersen

Hans Rohlof

James Jaranson

Jennifer Escala

Jens Modvig

Jeroen Knipscheer

Jill Heine

Jim Jaranson

Joost Den Otter

Jørgen Thomsen

José Quiroga

Juliet Cohen

June Lopez

Karen Hanscom

Karen Teshuva

Laura McDonald

Laurie Charles

Laurie Pearlman

Lena Barrett

Lilla Hardi

Lynn Michalopolous

M.J.J.Hoejenbos,

Maggie Zraly

Margriet Blaauw

Marie Brasholt

Marion Staunton

Mark Drumbl

Mary Bunn

Matthew Friedman

Mauro Palma

Megan Berthold

Michael Brune
Michael Grodin Nihan

Aksakalli

Nora Sveaass

Oliva Espin

Onder Ozkalipci

Paula Minguell

Peter Polatin

Peter Scharff Smith

Pierre Duterte

Raquel Gonzalez

Rina Ghafoerkhan

Roger Finke

Sarah Heke

Sara Lopez

Sebnem Fincanci

Shannon Dorsey

Shannon Golden

Sherein Ghaleb

Siroos Mirzaei

Sotheara Chhim

Steve Wright

Steven Miles

Stuart Grassian

Stuart Turner

Sue McAndrew

Sumru Bilge-Johnson

Teresa Gonzales

Therith Chy

Thomas Wenzel

Ton Haans

Tony Reeler

Touraj Ayazi

Trudy Mooren

Uwe Harlacher

Victor Igreja 